\title{
MÁS ALLÁ DE LOS PIRINEOS: LA IMAGEN DE LA CIENCIA ESPAÑOLA EN LOS LIBROS DE LOS VIAJEROS CHECOS A FINALES DEL SIGLO XIX E INICIOS DEL SIGLO XX ${ }^{1}$
}

\author{
por JANA ČERNÁ
}

(Universidad de Bohemia Occidental)

\begin{abstract}
Resumen
El objetivo del estudio es presentar la imagen de la ciencia y la educación españolas en las obras de los viajeros checos en el siglo XIX y principios del XX (especialmente de Ota Pinkas, Jaroslav Guth, Václav Kybal, Josef Müldner, Jan Rambousek, Karel Čapek $\mathrm{y}$ otros). Se dirige fundamentalmente a las características del ambiente intelectual español que los viajeros checos (y no solo ellos) percibieron como "específicamente español". En particular, se examina, en relación con la naturaleza del conocimiento científico, el problema de la "alteridad" española, el conocimiento árabe y su influencia sobre la cultura española, el misticismo español, el irracionalismo, el supuesto fanatismo o la así llamada abulia. En el contexto de los debates sobre la europeización de España y la polémica sobre la existencia de una ciencia española y el Renacimiento, también se presentan las características checas del Siglo de Oro español o la reflexión hacia la necesidad de europeización del conocimiento español. Aunque, en algunos aspectos, las opiniones de los intelectuales checos coinciden con las ideas de aquella época sobre la naturaleza del "espíritu español", no cuestionan la importancia o incluso la existencia de la ciencia española o del Renacimiento, sino que las presentan (desde una perspectiva histórica) como singulares y dignas de atención.

Palabras clave: viajeros checos; siglo XIX y XX; ciencia española; "alteridad" española; Siglo de Oro español; misticismo español; abulia; europeización
\end{abstract}

Beyond the Pyrenees: Image of Spanish Science in the Books of Czech Travelers in the Late Nineteenth and Early Twentieth Centuries

\begin{abstract}
The aim of the study is to offer an image of Spanish science and education in the works of Czech travellers of the nineteenth and early twentieth century, especially Ota Pinkas, Jaroslav Guth, Václav Kybal, Josef Müldner, Jan Rambousek, Karel Čapek, but also others. The study focuses on those characteristics of Spanish intellectual environment which Czech travellers (and others) perceived as 'specifically Spanish'. We examine the issue of Spanish 'otherness', Arab knowledge and its influence on Spanish culture, Spanish mysticism, irrationalism, alleged fanaticism, and the so-called 'abulia' and their relation to the nature of scientific knowledge. In the context of discussions on Europeanisation of Spain and controversy about the existence of a Spanish science in the Renaissance, we also examine Czech descriptions of the Spanish Golden Age and reflections on the need of Europeanisation of Spanish knowledge. Although in
\end{abstract}

1 El artículo es resultado del proyecto SGS-2016-052 Pensamiento Filosófico Español. 
some respects, the views of Czech intellectuals coincided with contemporary opinions regarding the nature of the 'Spanish spirit', they neither questioned nor denied the importance or even the very existence of Spanish Renaissance science. Instead, they tended to present them, from a historical perspective, as unique and worthy of attention.

Keywords: Czech travelers; 19th and 20th century; Spanish science; Spanish 'otherness'; Spanish Golden Age; Spanish mysticism; abulia; Europeanisation

Entre los ámbitos checo y español, el "corazón" y la "cabeza" de Europa, tuvieron lugar abundantes contactos desde hace muchos siglos, como ya ha sido ampliamente documentado y analizado desde diferentes perspectivas por historiadores e hispanistas checos y españoles. ${ }^{2}$ La historiografía también ha seguido las huellas de los viajeros checos que desde el siglo XX pasaron por los Pirineos. ${ }^{3}$ Sus motivos y razones para viajar a España fueron variadas: desde las religiosas, diplomáticas, científicas o artísticas, hasta las exclusivamente personales, alimentadas por la curiosidad y el deseo de conocer un país desconocido y diferente, envuelto en un velo de misterio y poesía. ${ }^{4} \mathrm{El}$ interés particular de los viajeros checos por conocer España fue creciendo paulatinamente a finales del siglo XIX y principios del siglo $\mathrm{XX}$, cuando se puede apreciar un aumento general del interés por viajar. ${ }^{5}$ Entre las personas que viajaron a la Península Ibérica y dejaron testimonios escritos, encontramos a escritores, pintores, científicos y otros intelectuales. En este texto prestaré atención a las imágenes de España que en sus obras retratan, ante todo, el escritor y restaurador, Ota Pinkas (1849-1890); el escritor y secretario general del Comité Olímpico Internacional, Jiří Guth (1861-1943); el historiador y diplomático, embajador de Checoslovaquia en España entre 1927 y 1936 y en México entre 1935 y 1938, Vlastimil Kybal (1880-1958); el pedágogo y escritor, Josef Müldner (18801954), el escritor, Jan Václav Rosůlek (1894-1958), el pintor y periodista, Jan Rambousek (1895-1976), el escritor católico Jaroslav Durych (1886-1962), el médico

2 Entre los historiadores checos más importantes que han tratado las relaciones checo-españolas se encuentran Bohdan Chudoba, Josef Polišenský, Bohumil Bad’ura, Josef Forbelský, Pavel Štěpánek, Simona Binková o Pavel Marek.

3 Para una perspectiva breve y general véase, por ejemplo, Antonio PEDAUÉ, "Las relaciones hispano-checas a lo largo de la historia. Aproximación a algunos períodos de particular interés", in: Josef Opatrný (ed.), Las relaciones checo-españolas, Praha 2007, pp. 9-23.

4 Sobre los "específicos españoles", véase más adelante. Simona Binková menciona que España, por su carácter único y específico, en particular la resistencia a la industrialización y la modernización (al contrario de otros países europeos), atraía a almas románticas de poetas y pintores. Simona BINKOVÁ, "La imagen de España en Bohemia de finales del siglo XIX. (Los libros de viaje de Jiří Guth, Pavel Durdík y Erazim Vlasák)”, in: J. Opatrný, Las relaciones checo-españolas, pp. 199-217. Igual para Josef Müldner, España es el país que atrae a los "soñadores“ véase Josef MÜLDNER, Španělsko včera a dnes [España ayer y hoy], Praha 1937, p. 18.

5 Después de los períodos de guerras y revoluciones de finales del siglo XIX, el ambiente europeo se estabilizó parcialmente; décadas de entreguerras del siglo XX representaron un período de prosperidad económica, que dio origen a la expansión del turismo; viajar dejó de ser un privilegio de la nobleza y de la gente rica. Cf. BINKOVÁ, La imagen, p. 199 y Josef OPATRNÝ, "La imagen de España entre los viajeros checoslovacos de entreguerras. No solamente Karel Čapek”, in: J. Opatrný (ed.), Las relaciones, p. 219 . 
Erazim Vlasák (1864-1904) y, por fin, el filósofo, escritor y periodista destacado Karel Čapek (1890-1938). ${ }^{6}$

A pesar de que eran hombres de diferentes profesiones, formaciones intelectuales y personajes diversos, en sus descripciones y representaciones de la "realidad española" encontramos una cantidad de aspectos idénticos o similares que en cierta medida corresponden con las ideas y concepciones sobre la "esencia de España" de la época. Dejando fuera de nuestro interés los que nos muestran unas impresiones generales, populares y bastante trivializadas (España como el país del vino, sol, mujeres hermosas, flamenco y corridas), vamos a analizar aquellos aspectos que los viajeros checos consideraron como las causas de los productos específicos del intelecto español. También se prestará atención al tema de la educación y la ciencia españolas, que (a diferencia de la belleza de las mujeres españolas o la calidad de los vinos españoles) ha sido cuestionada o completamente negada en la historia del pensamiento europeo (sobre la base de varios motivos y prejuicios).?

6 Hay que destacar que no es nuestra intención desarrollar un debate sobre la "Leyenda Negra" española, el "ser de España" o "polémica sobre la ciencia española" en general (el tema lo hemos tratado, por ejemplo, en el texto ¿Qué se debe a España?: Spor o význam Španělska v evropských intelektuálních dějinách, in: Dějiny - teorie - kritika. Además, sobre tal problemática ya existen numerosos trabajos). Tampoco queremos buscar elementos caractéristicos de la "interpretación checa" y analizarlos en el contexto "general". El objetivo del artículo es solo presentar y clasificar varias "imágenes" de la ciencia y educación españolas que podemos encontrar en los libros de los viajeros checos a finales del siglo XIX e inicios del siglo XX. Es decir, presentar el tema aún no trabajado desde la perspectiva elegida. Se trata del primer acercamiento que puede servir como punto de partida para el análisis de otros investigadores y que, por supuesto, podría (y debería) ser estudiado más detalladamente y profundamente en un contexto más amplio (podría ser discutido, por ejemplo, en qué medida las "observaciones" y testimonios de los autores checos con clichés fijos que circulaban en el discurso transnacional fueron desarrollados no solo por estos autores checos, sino también por los guías turísticos e incluso por los propios autores españoles). Los criterios usados para la selección de los textos analizados han sido los siguientes: han sido elegidos autores de diferentes estratos sociales, diferentes orientaciones políticas y profesiones, además, no existen muchos otros trabajos al respecto. Que yo sepa, no hubo ninguna mujer entre los viajeros checos que hubiera dejado un testimonio escrito.

7 De manera simplificada, la discusión sobre la existencia de la ciencia y la filosofía españolas puede interpretarse: 1) en el nivel metodológico (la problemática de definir ciencia, "lo científico", racionalidad y "grandes personalidades" en el contexto de la Ilustración y positivismo), 2) en el nivel histórico y político (las consecuencias de la leyenda negra antiespañola; el conflicto entre conservadurismo y el progresismo). Los comienzos de la llamada polémica de la existencia de la ciencia española están vinculados al siglo XVIII y al enciclopedista francés Nicolas Masson de Morvilliers, quien en la Encyclopédie Méthodique (1782) bajo el lema Espagne escribió que Europa no debía nada a España; percibió a los españoles como a una nación ignorante, perezosa y supersticiosa. Hablando sobre la ciencia, según Morvilliers, España es el país más atrasado e impotente de toda Europa véase Nicolás Masson de Morvilliers, in: La polémica de la ciencia española. Selección de Ernesto y Enrique García Camarero, 5; Masson de Morvilliers, Geographie, in: Nouvelle Encyclopédie, 1782 , tomo 1, p. 565, citado según Julio CARO BAROJA, El mito del carácter nacional, Madrid 2004, p. 104. Véase también José Luis ABELLÁN, Historia crítica del pensamiento español I. Metodología e introducción histórica, Madrid 1979, p. 42. Compara Sebastián QUESADA MARCO, Historia intelectual de España, Madrid 2004, p. 125. El texto de Morvilliers provocó reacciones indignadas en España y desató el debate que se conoce como la polémica de la ciencia española, aunque pronto se extendió a otras áreas del conocimiento. Para leer más sobre la existencia de la ciencia española, 


\section{¿Dónde comienza África? La alteridad y las "peculiaridades" del mundo español}

Probablemente, la afirmación más conocida sobre las diferencias del ambiente español con el que los lectores checos pudieron familiarizarse fue el de Karel Čapek y su Výlet do Španěl [Viaje a España]. Literalmente escribe: "Es desértico y grande, árido como el desierto, misterioso como el Sinaí; no sé cómo decirlo: es otro continente, no es Europa." ${ }^{8}$ En su opinión, España está ensombrecida por un misterio impenetrable; es más vieja que Europa, más rigurosa y más desolada, no en el sentido de la melancolía, sino solemne y extraña, áspera y exaltada. Y, sobre todo, debido a su paisaje diferente, el escritor no duda en compararlo con África. Sin embargo, la visión de Čapek no es aislada, se puede encontrar también en las obras de otros intelectuales, (no solamente) checos. Jaroslav Durych escribe en su Pout' do Španělska [Peregrinación a España] (1929) que se trata de un país "duro, crudo, desnudo, abandonado, gris, pedregoso, con grava, arenoso, árido, sin sombra, desolador, rojizo, con un atardecer de color malva melancólico, y de noches negras desérticas, por las mañanas vanamente sediento de gotas de agua, aquí ya se siente África.” A continuación, añade que es una tierra majestuosa y extrañamente hermosa, santa y sublime. ${ }^{9}$ Del mismo modo, Vlastimil Kybal, hablando de Andalucía (O Španělsku. Cestovní dojmy a úvahy [Acerca de España. Impresiones y reflexiones de un viaje], 1928), constata: "el país y el pueblo dan testimonio evidente del hecho de que Europa ha terminado aquí y ha comenzado África". ${ }^{10}$

Jiří Guth (Causerie z cest, řada I, Španělsko [Causerie de viajes, serie I, España], 1891) entró por primera vez en las tierras hispanas a su regreso de Argelia, feliz de estar de vuelta a su continente natal. Sin embargo, España es para él un país extraño y aún poco visitado, aunque tiene muchas curiosidades y sitios de interés histórico, mucho más de lo que puede ofrecer cualquier otro país. ${ }^{11}$ De modo semejante lo expresó Ota Pinkas (1880): la literatura y el arte españoles, a diferencia de las culturas inglesa, francesa o italiana, son "casi totalmente desconocidos" en

véase, por ejemplo, Jana ČERNÁ, “¿Qué se debe a España?: Spor o význam Španělska v evropských intelektuálních dějinách", in: Dějiny - teorie - kritika, pp. 230-245. Ciertos estereotipos relacionados con esta discusión e ideas se reflejaron también en el ambiente checo, como se mostrará en la siguiente parte del estudio. Sobre la problemática de la así llamada leyenda negra veáse Julián JUDERÍAS, La leyenda negra de España, p. 102. Compara, por ejemplo, Víctor NAVARRO BROTÒNS - William EAMON, Más allá de la Leyenda Negra. España y la Revolución Científica. Beyond the Black Legend: Spain and the Scientific Revolution, Valencia 2007, p. 9. Más recientemente, por ejemplo, Monica Bolufer, Xavier Andreu, etc.

Karel ČAPEK, Cesta do Španěl, Praha 1940, p. 20.

9 Jaroslav DURYCH, "Pout' do Španělska", in: Michal Šiml (ed.), Tři toulky Evropou [Tres viajes por Europa], Praha 1993, pp. 85, 93. Ve las ciudades españolas como semi-romanas y semi-moriscas, como el extranjero inmenso, radical para nosotros (p. 86). Pero escribiendo sobre Madrid, dice que la capital española se parece a Viena. Sin duda, según Durych, Madrid se ve mucho mejor en la realidad que en los textos de Ramón Gómez de la Serna. DURYCH, Pout', p. 133.

10 Vlastimil KYBAL, O Španělsku. Cestovní dojmy a úvahy [Sobre España. Las impresiones y reflexiones de viaje], Praha 1928, p. 30.

11 Jiří GUTH, Causerie z cest, řada I, Španělsko [Causerie de viajes, serie I, España], pp. 18-20. 
el ambiente checo, la tierra que los viajeros y turistas "comunes" evitaban, aunque España merece mucha más atención por parte de los estudiosos de lo que ha recibido hasta ahora. ${ }^{12}$ Igual, la gente española es "interesante", diferentes de los pueblos de otros países. ${ }^{13}$ Jan Rambousek (Toulky po Španělsku [Paseos por España], 1926) también ve a España como un "país especial" y, al final de su viaje, admite que en realidad está renunciando al esfuerzo de comprender ese espíritu específico. ${ }^{14}$ Por último, también Jan Václav Rosůlek habla sobre España como un país misterioso (Listky ze Španěl [Cartas de España], 1929) y afirma que se llama África europea, ya que se considera que Budapest es el comienzo de la Asia europea. Sin embargo, al instante la imagen de los Pirineos como la frontera entre Europa y África, que apareció de forma explícita por primera vez en la obra de Teófilo Gautier Tras los montes o Le Voyage en Espagne (1843), la rechaza y la confronta con sus impresiones de Barcelona, una gran ciudad que con su existencia propia testifica sobre su disparidad con África. ${ }^{15}$ Sin embargo, no duda sobre la alteridad del ambiente español y es consciente de que para un conocimiento adecuado del país tras los Pirineos será necesario revisar muchos conceptos y opiniones erróneos. ${ }^{16}$

Aunque no todos los autores asemejan explícitamente a España con África, coinciden en lo siguiente: es diferente, extraña, misteriosa y para el viajero checo es hasta ahora casi desconocida. Sobre la diferencia de España con respecto a otros países europeos, no sólo hablaron los autores checos, sino también los intelectuales de otros países e incluso los españoles mismos. ${ }^{17}$ Uno de ellos fue también Ángel Ganivet (1865-1898), autor influyente e inspirador no sólo para la Generación del 98, sino también bien conocido entre los intelectuales extranjeros, es decir, también los checos.$^{18}$ Ganivet, en su obra Idearium Español, habla de la extrañeza de España

12 Müldner en su Španělsko včera a dnes [España ayer y hoy] (1937) dice, viajando a las Islas Baleares, que hubiera sido menos complicado llegar a Nueva York, Brasil o México. MÜLDNER, Španělsko, p. 7. Y Jaroslav Durych declara que es más fácil llegar a Filipinas o al polo norte que a Mérida (a dónde él llegó por coincidencia y presumía de ser tan original). DURYCH, Pout', p. 90.

13 Ota PINKAS, Cesta po Španělích [Viaje por España], Praha 1880, pp. V-VI.

14 Jan RAMBOUSEK, Toulky po Španělsku [Paseos por España], Praha 1926, p. 74.

15 Jan Václav ROSŮLEK, Lístky ze Španěl [Cartas de España], Praha 1929, pp. 7-8. Similarmente fascinado por Barcelona fue Erazim Vlasák tres décadas antes. Mientras que el paisaje del "lejano Madrid", según él, más bien se parecía a un desierto. Erazim VLASÁK, Cesta do Madridu [Viaje a Madrid], Praha 1899, p. 100.

16 "De verdad, crucen los Pirineos, y todo será un pueblo desconocido para ustedes; un pueblo que requiere una cuidadosa atención para destruir todos los conceptos erróneos que se han acumulado a lo largo de décadas." ROSŮLEK, Listky, p. 47.

17 Por ejemplo, el novelista y diplomático Juan Valera (1824-1905) describe varios curiosos encuentros entre el mundo hispano y europeo. En su ensayo Sobre el concepto que hoy se forma de España (1868) presenta las preguntas particulares que le dieron los europeos: si en España se cazan los leones como en África o si los españoles conocen el té. Valera concluye que la mayoría de los europeos percibe a la nación española de una manera muy distorsionada e injusta. Declara que los europeos ignoran que los españoles realmente eran y son. Juan VALERA, "Sobre el concepto que hoy se forma de España”, in: J. Valera, Obras completas, Madrid 1958, tomo 3, pp. 651-945.

18 Por ejemplo, Vlastmil Kybal menciona Idearium Español (junto con Por tierras de Portugal y de España de Unamuno o El alma castellana de Azorín) en la lista de la literatura esencial sobre España). Es obvio que leyó estos libros (veáse más adelante). Kybal también estuvo en contacto escrito con 
en comparación con otros países europeos que también son causa de las anomalías de su historia. ${ }^{19}$ Por tanto, tras los Pirineos hay muchas especificidades; esta conclusión se puede aplicar también al mundo intelectual, es decir, también a la ciencia y el conocimiento español en general, como lo mostramos a través de análisis de los textos de los viajeros checos, mencionados anteriormente (y que en varios aspectos coinciden con las opiniones de la época).

\section{La bailarina y el monje jesuita. Herencia árabe}

Unos de los primeros y principales momentos que formaron el carácter peculiar de la cultura española en general y, más específicamente, de su ciencia y educación, fueron (no sólo) según los intelectuales checos los contactos con la ciencia y cultura árabe. Casi todos los viajeros checos aprecian altamente el valor y el nivel de la cultura árabe, hasta se puede hablar sobre la fascinación por la cultura árabe y su impacto sobre España. Según Kybal y Müldner, el carácter propio de España se formó gracias al antagonismo de la cultura árabe y la española a partir del siglo VIII . ${ }^{20}$ En la España musulmana, según Kybal, la cultura espiritual estaba en un nivel que la convertía en la región más educada de Europa y que tuvo una gran influencia en el carácter de la cultura española posterior. Sus huellas que luego quedaron en España formaron un carácter particular, único en toda Europa. ${ }^{21}$ En cuanto a la ciencia, la cultura árabe, según Kybal, destacaba en los campos de las “ciencias del espíritu” (historia, filosofía, poesía, ciencia jurídica y filología), así como en las exactas (matemática, astronomía y medicina) ${ }^{22}$ tanto, que en comparación con ella la cultura cristiana de la época era muy pobre en su alcance y contenido. ${ }^{23}$ Otro impulso igual de influyente para la ciencia y la cultura española y europea en general fue el encuentro con el Nuevo Mundo, gracias al cual España se convirtió en un poder mundial. ${ }^{24}$

De manera similar, Ota Pinkas afirma que en el momento de la dominación de los "moros" (musulmanes) en España, no sólo creció la riqueza, sino también la

\footnotetext{
Unamuno. En el contexto de este artículo, el trabajo de Kybal muestra una visión más profunda del pensamiento y la cultura españolas, gracias a su educación y también gracias a su estancia en España como embajador (1927-1933). Kybal estaba familiarizado con los textos de viajeros checos como los de Pinkas, Rambousek, Guth y Durdík.

19 “España es una Península ó con más rigor «la península»; porque no hay península que se acerque más a ser isla que la nuestra. Los Pirineos son un istmo y una muralla; no impiden las invasiones, pero nos aislan y nos permiten conservar nuestro carácter independiente. En realidad nosotros nos hemos creído que somos insulares y quizás este error explique muchas anomalías de nuestra historia" Ángel GANIVET, Idearium español, Granada 1897, p. 36. Ángel GANIVET, Španělské idearium, Chomutov 2007, p. 21.

20 Vlastimil KYBAL, Velikáni španělských dějin [Los grandes de la historia española], Praha 1935, p. 8. Kybal compara este proceso con el surgimiento del estado checo del antagonismo de germanicidad y eslavismo. Compara MÜLDNER, Španělsko, p. 16.

21 KYBAL, Velikáni, p. 9.

22 Kybal se inspira obviamente en la clasificación de las ciencias formulada por Wilhelm Dilthey.

23 KYBAL, Velikáni, p. 10.

24 Ibidem, pp. 30-32.
} 
educación. ${ }^{25}$ En su descripción de la Biblioteca de El Escorial menciona en primer lugar los escritos árabes, aprecia la antigua coexistencia de las tres culturas en Toledo y, por el contrario, condena la insensible persecución del conocimiento árabe, que también se reflejó en la quema de libros. ${ }^{26}$ Expresa su sorpresa de que Carlos $\mathrm{V}$, como soberano iluminado, patrón y protector del arte, era "enemigo cruel del arte morisco" que lo reformaba de forma sustanciosa, destruyendo su originalidad y belleza, o hasta lo eliminaba. Aunque al final de su libro destaca que ante todo la idea del cristianismo permitió realizar los admirables y magníficos monumentos en España, su texto anterior representa el testimonio sobre su actitud muy positiva hacia la cultura árabe. Incluso, en cierto sentido, ve al legado del mundo árabe, en comparación con el mundo "culto" posterior, como superior a él: según Pinkas, "los moros viejos, estos así llamados 'bárbaros', sabían convertir los desiertos en paraísos - todo lo contrario al mundo posterior, más culto."27

Esta tendencia se encuentra aún más articulada en los trabajos de Jiř́ Guth y Jan Václav Rosůlek. Guth queda fascinado por la arquitectura árabe, los asombrosos palacios de los gobernantes moros, que evocan placer y alegría, confrontándolos con la rigidez y austeridad del arte cristiano, representado principalmente por El Escorial. Para Guth, la alegría y ligereza del arte árabe puede ser simbolizada por una bailarina de ballet - confrontándola con la frialdad cristiana del monje jesuita. ${ }^{28}$ Niega considerar El Escorial como la octava maravilla del mundo, ${ }^{29}$ criticando el tratamiento insensible de los gobernantes de la Casa de Austria hacia los monumentos árabes (por ejemplo, hacia el interior del Alcázar de Sevilla) y lamenta la riqueza, la prosperidad, el esplendor y la gloria desaparecidos de la Andalucía después de su toma por los Reyes Católicos..$^{30}$ Del mismo modo, Jan Václav Rosůlek pone en contraste la frialdad de El Escorial (y otras construcciones de los Habsburgo) con la belleza de la arquitectura árabe. ${ }^{31}$ Escribe sobre la Andalucía salerosa, la Córdoba morisca, la ciudad de Séneca, su carácter y encanto específico, que no han sido eliminados ni por los siglos, ni por la brutalidad humana o la religión bárbara. ${ }^{32}$ También queda fascinado por Granada; debido a su Patio de los Leones, según él, no sólo merece la pena visitar esta ciudad, sino también toda España. ${ }^{33}$

La herencia cultural árabe es apreciada también por Karel Čapek, pero no en contraste con la tradición cristiana, sino al contrario: Čapek destaca la fantástica

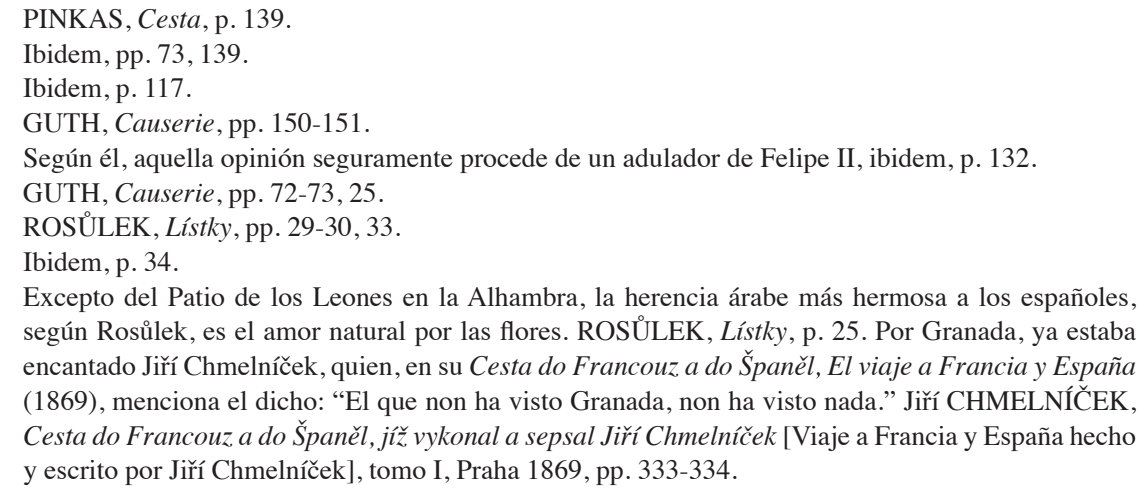
según Rosůlek, es el amor natural por las flores. ROSŮLEK, Lístky, p. 25. Por Granada, ya estaba encantado Jiří Chmelníček, quien, en su Cesta do Francouz a do Španěl, El viaje a Francia y España (1869), menciona el dicho: "El que non ha visto Granada, non ha visto nada." Jiří CHMELNÍČEK, Cesta do Francouz a do Španěl, jižz vykonal a sepsal Jiř́ Chmelníček [Viaje a Francia y España hecho y escrito por Jiří Chmelníček], tomo I, Praha 1869, pp. 333-334. 
"unidad de historia, dioses y culturas" que se manifiesta no sólo en Toledo, ${ }^{34}$ sino en toda España. Cuando habla de la Giralda como el "símbolo emblemático de Sevilla", recuerda que es un alminar moro con campanas cristianas, que es romano y visigodo en su base. Según su opinión, este es el caso de toda España: tiene fundamentos romanos, lujo morisco y sentido católico. ${ }^{35}$ Por otro lado, se pueden mencionar las opiniones de Jaroslav Durych como poeta y novelista de fuerte orientación católica. Con cierta ironía escribe que en su época es sintomático expresar lástima por el hecho de que España no ha quedado bajo el dominio árabe; pero si se hubiera quedado la raza árabe, España nunca se habría convertido en la cabeza de Europa. ${ }^{36}$

\section{Por tierras del "demonio del Sur" ¿Inquisición y "fanatismo" de la nación española como obstáculo para el desarrollo de la ciencia?}

En la discusión general de la existencia (o naturaleza) de la ciencia española, se puede observar a menudo el siguiente argumento: en el país donde la racionalidad fue reprimida por la fe y sobre todo silenciada por el dogmatismo de la Iglesia católica, no se podía desarrollar ni ciencia, ni filosofía; no hubo un pensamiento crítico. Por ejemplo, los progresistas españoles del siglo XIX no dudaron del efecto devastador de la Inquisición sobre la cultura española, solo disputaron si suprimía toda actividad intelectual, incluido el arte, o sólo el conocimiento científico y la filosofía. ${ }^{37}$ Además de otros motivos, estos argumentos contribuyeron a desarrollar el discurso de la leyenda negra antes mencionada y, de hecho, se convirtieron en unas de sus piedras fundamentales. ${ }^{38}$ Incluso en los libros de los viajeros checos hay referencias a la influencia desfavorable de la Inquisición sobre la cultura española, pero no conducen a conclusiones sobre la ausencia de un pensamiento racional, científico o filosófico en la península ibérica o la imposibilidad de la "modernización" de la nación española.

Los comentarios sobre las males de la Inquisición y sus prácticas crueles se pueden encontrar en el trabajo de Ota Pinkas, sobre sus horrores habla también Vlastimil Kybal, pero a pesar de esto, valora la historia de España como la historia de una gran nación. ${ }^{39}$ Kybal también rechaza los prejuicios sobre el fanatismo del pueblo español, según él son completamente falsos. ${ }^{40}$ Los españoles, según Kybal, no son

34 ČAPEK, Cesta do Španěl, p. 31

35 Ibidem, p. 71. Véase OPATRNÝ, La imagen, pp. 223-224.

36 DURYCH, Pout', pp. 110-111. Durych tiene una actitud negativa hacia el "paganismo" en general (por ejemplo, véase el pasaje donde describe el tesoro de la Catedral de Sevilla, oro y esmeralda "indios". Ibidem, pp. 86, 123.

37 Antonio SANTOVEÑA SETIÉN, Marcelino Menéndez Pelayo: revisión crítico-biográfica de un pensador católico, Santander 1994, pp. 144-145.

38 Véase Julián Juderías, quién como el primero define la leyenda negra en el significado que se usa hoy: como el estereotipo de ver a España como el país inquisitorial, ignorante, fanático, incapaz de figurar entre los pueblos cultos lo mismo ahora que antes, enemigo del progreso y de las innovaciones. Julián JUDERÍAS, La leyenda negra de España, Madrid 2014, p. 102.

39 KYBAL, O Španělsku, p. 109.

40 Ibidem, p. 101. 
religiosos prácticantes (su mayoría permanece en la Iglesia sólo por costumbre); por lo que las iglesias tanto en los pueblos como en las ciudades se encuentran semi-vacías. ${ }^{41}$ Por otro lado, Jan Václav Rosůlek observa que los únicos dos lugares donde uno nunca se encuentra sólo en España son en la iglesia y en las plazas de toros. ${ }^{42}$ Sin embargo, tampoco habla sobre el fanatismo de los españoles, además rechaza la opinión de prácticas específicas de la Inquisición española, según él eran parecidas en toda Europa. ${ }^{43}$

La condena de las prácticas de la Inquisición y la tesis del fanatismo a menudo se relacionan directamente con la persona de Felipe II y deberían ser interpretadas también en el discurso de la leyenda negra. Felipe era presentado como un demonio, fanático, dogmático limitado y hombre cruel. ${ }^{44}$ Algunas de estas características simplificadoras penetraron también en el ambiente checo. Según Jiří Guth, Felipe II apoyaba y alimentaba la Inquisición intensamente; era un rey de mente piadosa, pero no de hechos piadosos. Considera a Felipe un fanático y un gobernante extraño y cruel.$^{45}$ Jan Rambousek, hablando de El Escorial, caracteriza a su fundador, Felipe II, como un hombre fanático y melancólico. ${ }^{46}$ Vlastimil Kybal también habla de Felipe como melancólico (en el sentido de la enfermedad ancestral, no como moda de la época), un hombre serio y reservado (refiriéndose a Pedro Martiro, un humanista español de origen italiano). Menciona que los protestantes le llamaban el "Demonio del Sur, el Demonio del Mediodía" por su fanatismo político-religioso, y también escribe sobre su implacabilidad política a la crueldad (incluso hacia su propia sangre). Además, Kybal afirma que Felipe II defendía la ortodoxia a través de la Inquisición y la pasión de su poder se fundía con su pasión por la fe.

Sin embargo, enfatiza que el Renacimiento religioso iba mano a mano con el Renacimiento científico, literario y artístico y destaca la estrecha relación de Felipe con la "cultura científica" (igual como con la religiosa y la artística) ${ }^{47} \mathrm{~A}$ pesar de algunas opiniones negativas del carácter de Felipe u otros delitos de su reinado, Kybal claramente rechaza la idea de considerar a Felipe como un "demonio del sur" o como un Satanás que gobernó en el nombre de Cristo (C'était Satan régnant au

41 Ibidem, pp. 101-102.

42 ROSŮLEK, Lístky ze Španěl, p. 24.

43 “¿Inquisición? Conquistadores? ¡No! Todo lo demás es lo mismo [...] en todo el mundo - la viuda blanca y negra“ (es una alusión a la novela de Ramón Gómez de la Serna del mismo nombre). Ibidem, pp. 60-61.

44 Javier PUERTO SARMIENTO, La leyenda verde. Naturaleza, sanidad y ciencia en la corte de Felipe II (1527-1598), Valladolid 2003, p. 7. Cf., por ejemplo, JIŘÍ CHALUPA, Španělsko, Praha 2005, pp. 75-78. Chalupa afirma que es difícil encontrar a un monarca más difamado que Felipe II. Una gran influencia para la representación de Felipe II casi como un monstruo tuvo La apología del príncipe d'Orange. Ya durante el reinado de Felipe II surgió así llamada leyenda blanca creada por los admiradores de Felipe. Con el motivo del cuarto centenario de la muerte de Felipe (1998), surge la leyenda rosa, intentando evitarse las versiones "negra" y "blanca", tratando de respetar la realidad histórica tanto como era; describiendo a Felipe como un gobernante típico del Renacimiento, con sus pros y sus contras. Véase Joseph PÉREZ, La leyenda negra, Madrid 2009.

45 GUTH, Causerie, pp. 131-132.

46 RAMBOUSEK, Toulky, p. 62.

47 KYBAL, Velikáni, p. 40. 
nom de Jésus Christ, como le llamó Víctor Hugo). En su breve estudio sobre Felipe II, Kybal termina subrayando el hecho de que éste fue un hombre culturalmente sensible (genial hacia los artistas), hambriento de conocimiento (por ejemplo, realizó sus propios comentarios sobre Erasmo), un amante de los libros y manuscritos, y un místico piadoso. Como ha sido ya mencionado arriba, en los textos de los viajeros checos no se puede encontrar una característica del pueblo español como pueblo fanático, incapaz del progreso científico, o, tampoco se mencionan la tesis de la ausencia de la ciencia española y la debilidad de la educación como resultado de la acción de la Inquisición. Por el contrario, V. Kybal destaca (además de otras cosas) que durante el reinado de Felipe II nació la Edad de Oro, para la cual era típica "la síntesis del platonismo, ascetismo y misticismo" ${ }^{48}$ La educación de la Edad de Oro, por supuesto, no se limitó sólo a estas corrientes ${ }^{49}$ pero ha sido ante todo el misticismo español que entró en la conciencia general como una corriente principal del Renacimiento español (definiendo el carácter de la filosofía española de su tiempo).

\section{¿Éxtasis e intuición en lugar de la razón? Misticismo y ensoñación español vs. racionalidad científica}

No sólo en el ambiente checo, el misticismo español ${ }^{50}$ se percibe como esencial para el alma española. Esta opinión sirvió como "argumento" definitivo en la polémica de la ciencia española como conclusión para demostrar su ausencia. Por ejemplo, según Manuel de Revilla (1846-1881), doctor en Leyes y Filosofía, la ausencia de conocimiento científico debe atribuirse al "espíritu nacional español", que según él, tiende al misticismo y la "ensoñación" en detrimento del pensamiento racional independiente..$^{51}$ Del mismo modo, Miguel de Unamuno, uno de los filósofos españoles modernos más conocidos en el mundo, afirma que los términos "ciencia" y "español" son más bien mutuamente excluyentes y que los únicos filósofos españoles fueron los místicos..$^{52}$

Václav Kybal también conocía las observaciones de Unamuno con respecto al misticismo español ${ }^{53}$ (las cita en su texto sobre Santa Teresa de Ávila; a la que de-

48 Ibidem.

49 Véase más adelante.

50 Entre los representantes más destacados del misticismo renacentista español, que se basa en el misticismo de las corrientes medievales y contemporáneas, como el neoplatonismo, pertenecen Teresa de Cepeda y Ahumada (santa Teresa de Ávila), Luis de León y Juan de Yepes y Álvarez (San Juan de la Cruz).

51 ABELLÁN, Historia I, p. 43.

52 Miguel de UNAMUNO, O poevropštění, in: Unamuno, Španělské essaye, Brno 1997, p. 11. Compara Miguel de UNAMUNO, Sobre la europeización (arbitrariedades), in: Unamuno, Algunas consideraciones sobre la literatura hispanoamericana, Madrid 1968, p. 117. Veáse también Miguel de UNAMUNO, De Mística y humanismo, in: Unamuno, En torno al casticismo, Madrid 1996, pp. 130-131.

53 Kybal también estuvo en contacto escrito con Unamuno. Además, en el ambiente checo de la década de 1930, se publicó uno de los estudios originales del destacado hispanista checo Václav Černý (1905-1987) Rektora ze Salamanky boj o nesmrtelnou duši a uctívání smrti [Sobre la lucha por el alma inmortal y el culto a la muerte del rector salmantino]. Aquí menciona Černý a San Juan de la Cruz y a Teresa de Ávila como los estimados compatriotas de Unamuno. In: Václav ČERNÝ, Studie 
dicó uno de los seis capítulos sobre las seis personalidades más importantes de la historia de España, al lado de El Cid, Felipe II, Hernán Cortés, Cervantes y Goya).$^{54}$ Kybal habla sobre la congenialidad de la naturaleza de Santa Teresa y el alma española, es decir, la piedad profunda, hasta angelical, el entusiasmo de Don Quijote, el instinto de belleza sobrenatural, bondad y placer; en el instinto y entusiasmo basados en la inmensa contradicción entre los sueños y la realidad; igual como en el desdén por el mundo material, pasajero y sucio..$^{55}$ Junto con San Juan de la Cruz, según Kybal, Teresa es la representante más original del misticismo español del siglo XVI, y, al mismo tiempo, un brillo que iluminaba la religión, la literatura y el arte, en toda la sociedad de su tiempo ${ }^{56}$ En la actitud de Santa Teresa aprecia ante todo el hecho de que era una mujer, una mujer española, sensible y emocional, que a diferencia de los místicos (hombres), no se perdía en "contemplaciones y visiones metafísicas" ${ }^{57}$ Recuerda la afición de la obra de Santa Teresa por Felipe II, pero también, por ejemplo, por María Manrique de Lara, una noble española casada con el noble checo Vratislav II de Pernstein.

No es sorprendente que también Jaroslav Durych prestara una atención especial a Santa Teresa. Ávila, el lugar donde Santa Teresa nació, lo llama Durych "la cámara más preciosa de España" y describe expresivamente su visita al Colegio de Santo Tomás y la casa natal de Teresa. ${ }^{58}$ Los místicos españoles son mencionados también por otros viajeros checos. ${ }^{59}$ Por ejemplo, Jiří Chmelníček recuerda, viajando a Granada, a Luis de Granada, "el hombre santo, orgullo de la orden de los dominicos y autor de muchos excelentes libros ascéticos" ${ }^{60}$ Jiří Guth no olvida mencionar a Luis de León y su famosa aula ${ }^{61}$ durante su visita a Salamanca, y Jaroslav Durych habla sobre Burgos como "la ciudad de San Juan de la Cruz". ${ }^{62}$

Aunque en las obras de viajeros checos es posible encontrar tanto las tesis sobre la congenialidad del misticismo español y el alma española (animadas por la energía de Don Quijote), como las características de la nación española como mística, poética

o španělské literatuře, p. 304. Unamuno estuvo en contacto con el mundo checoslovaco gracias a la correspondencia con Ginés Gaga, en aquel momento el único profesor de español en Checoslovaquia. Para obtener más información sobre este tema, consulta la tesis de Vít Pokorný. Vít POKORNÝ, Jak známe Ernesta Renana a Miguela de Unamuna? Dva přední evropští intelektuálové v zrcadle české recepce [tesis de máster], Praha 2005, supervisor Juan A. Sánchez.

54 Esta es una colección de conferencias y debates para estudiantes universitarios checos, publicada en 1935 y dedicada a Ramón Menéndez Pidal, "en profundo respeto por la cultura española y sincero agradecimiento por la cooperación en la construcción de las relaciones culturales checoslovaco-españolas" en el momento de la misión diplomática de Kybal en España en los años 1927-1933.

55 Kybal, Velikáni, p. 53.

56 Ibidem, p. 51.

57 Ibidem, p. 52.

58 DURYCH, Pout', pp. 114-120.

59 Durante su visita a El Escorial, ya Lev Vilém z Kounic habló de la presencia de los manuscritos y las herramientas de escritura de Santa Teresa en la biblioteca del Escorial. Lva Viléma z Kounic Cesta z Janova do Hispánie, 1636, in: Simona BINKOVÁ (ed.), Česká touha cestovatelská [El Deseo viajero checo], Praha 1989, p. 184

60 CHMELNÍČEK, Cesta, p. 366.

61 Jiří GUTH, Za horama Pyrenejskýma [Más allá de las montañas de los Pirineos], Praha 1902, p. 159.

62 DURYCH, Pout', 123. 
y misteriosa (Pinkas, $\check{C}$ apek, Schwarzenberg ${ }^{63}$ ), no existe argumento que los relacione con la ausencia de pensamiento científico o filosófico ${ }^{64}$, por el contrario, como muestra el análisis siguiente, en sus textos encontramos la evaluación del Renacimiento español, de la ciencia y la educación modernas como avanzadas y notables.

\section{¿La Roma española, la rosa amarilla y la octava maravilla del mundo? Tesoros intelectuales de la Edad de Oro española}

El florecimiento excepcional e intenso de la cultura española se asocia principalmente con el siglo XVI y el comienzo del siglo XVII. Del mismo modo, los textos de los viajeros checos reflejan (de una manera más o menos comprensible) la admiración por la herencia cultural e intelectual de esta época. Describen no sólo las iglesias, sino también los bastiones de la educación, es decir, las universidades, los archivos, las bibliotecas y otras instituciones en las que se cultivaba o conservaba el conocimiento científico y la educación. En particular, su enfoque se concentra en Sevilla, El Escorial y Salamanca.

Sevilla, como puerto y puerta que conectó Europa con el Nuevo Mundo, disfrutaba de gran fama y admiración ante todo en su apogeo, es decir en el siglo XVI, pero para los viajeros no perdió su atractivo ni en los siglos XIX y XX. Encantados principalmente por su "esencia andaluza" y, de acuerdo con el proverbio español, hablaban de ella como de un milagro (Chmelníček, Guth). ${ }^{65}$ Ota Pinkas, refiriéndose al escritor alemán W. Hosäuse, la describe como ciudad de "poesía e historia,

63 También Bedřich Schwarzenberg habla en su obra Španělský deník a zrození revolucí sobre España como un país poético. Bedřich SCHWARZENBERG, Španělský deník a zrození revolucí [El diario español y el origen de la revolución], Praha 1937, p. 27.

64 Por ejemplo, según Bělič y Forbelský el misticismo renacentista español es un sustituto: la filosofía y la ciencia son sustituídas por el éxtasis y la intuición. Véase Oldřich BĚLIČ - Josef FORBELSKÝ, Dějiny španělské literatury [Historia de la literatura española], Praha 1984, p. 58. He intentado presentar a los lectores checos la variedad y especificidad del conocimiento científico y filosófico del Renacimiento español, entre otros textos, en dos monografías: J. ČERNÁ, Dál a dál : př́rodní tajemství Nového světa a španělská renesanční filosofie a věda [Más allá detrás de las columnas de Hércules: los misterios naturales del Nuevo mundo y la filosofiía y ciencia españolas], Praha 2016 e idem, Očitá svědecví: Španělsko, Nový svět a změna vědeckého komunikačního paradigmatu [Testimonios oculares: España, Nuevo Mundo y el cambio del paradigma comunicativo científico], Červený Kostelec 2012.

65 Guth escribe al comienzo de su texto sobre Sevilla "Quien no ha visto Sevilla. No ha visto la maravilla”, podobně Chmelníček. GUTH, Causerie, p. 27. Karel Čapek escribe sobre la lindeza sevillana como particularmente adorable y dulce. ČAPEK, Výlet, p. 63. Rambousek se centra principalmente en los tesoros del arte y la arquitectura de Sevilla, celebrándola como la ciudad de Murillo. RAMBOUSEK, Toulky, p. 47. Por otro lado, Vlastimil Kybal, aúnque aprecia algunos monumentos de Sevilla, ve a esta ciudad más bien como una fábula turística (más cómoda de creerla que refutarla). KYBAL, O Španělsku, p. 67. Es bastante sorprendente que Kybal, como historiador, no hace ningún comentario sobre el Archivo de Indias; se refiere sólo a la institución de la Casa de Contratación, habla principalmente de ésta como una institución económica; no refleja la dimensión científica de sus actividades; mencionando que se dedicó a "cuestiones técnicas" relacionadas con los viajes ultramarinos. KYBAL, Velikáni, pp. 21-22. 
alegría y placer, vida placentera, rosas y jardines de azahar"; incluso la considera como la ciudad española más agradable. ${ }^{66} \mathrm{Al}$ mismo tiempo, Sevilla es, según Pinkas, muy importante con respecto a su riqueza intelectual: habla de la Biblioteca Colombina como una de las más ricas de España, que contiene principalmente cartas y diarios del "famoso descubridor de América, Cristóbal Colón”, así como otras "rarezas históricas". Compara sus riquezas con las del Archivo General de Indias, que ofrece un "verdadero tesoro para el historiador de España" ${ }^{67}$ Sobre la Biblioteca Colombina como una de las más importantes, ricas y preciosas de España escribe también Jiří Guth, y comparte con el lector los sentimientos excepcionales que le llenaban al ver los libros antiguos, más concretamente, una cosmografía latina con notas manuscritas hechas por Colón. ${ }^{68}$

Los viajeros checos igualmente apreciaron la riqueza de la Biblioteca del Escorial, aunque el propio El Escorial no les gustaba; rechazaron considerarlo como la octava maravilla del mundo y lo relacionaron más bien con connotaciones negativas. Jan Václav Rosůlek recuerda que El Escorial representó al soberano del Imperio donde nunca se ponía el Sol, pero que él sentía frialdad y austeridad. ${ }^{69}$ Del mismo modo, Guth habla de la enormidad genial del Escorial; no es para disfrutar, todo lo contrario: pesa y provoca ansiedad debido a su frialdad y "estilo prisionero". Sólo explica cierta pena por no poder visitar el Panteón y la biblioteca porque se reconstruía en el momento de su visita. ${ }^{70}$ Mejor suerte tuvo Ota Pinkas, quien pudo visitar la "biblioteca de fama mundial" y apreciar sus riquezas, libros acumulados de todas las librerías reales y monásticas. Menciona una colección diversa de manuscritos que contienen fuentes cristianas, árabes, chinas, persas y hebreas, y también aprecia los globos colosales. ${ }^{71}$ La gran biblioteca con preciosos globos antiguos y muchas pinturas antiguas de españoles y otros maestros es también mencionada por Erazim Vlasák, ${ }^{72}$ la biblioteca de El Escorial y, sobre todo, una rara colección de manuscritos, apreciada también por Josef Müldner. ${ }^{73}$ Para Karel Čapek, El Escorial encarna la soledad monumental, el orgullo y austeridad. ${ }^{74}$ Jaroslav Durych lo considera un lugar noble y triste, y aunque conserva muchas cosas de valor artístico como histórico, no supera el promedio de lo que ya vio en su viaje por España. ${ }^{75}$ Según Kybal, “Eskurial” repele a través de su pedantería y estilo acuartelado y de templo. ${ }^{76}$

66 PINKAS, Cesta, p. 90.

67 Ibidem, pp. 93, 98. La importancia del Archivo de Indias como la Colombina es también recordada por Josef Müldner, quien menciona el número de volúmenes que contienen. MÜLDNER, Španělsko, p. 46.

68 GUTH, Causerie, pp. 81-83.

69 ROSU゚LEK, Lístky, pp. 47-50.

70 GUTH, Causerie, pp. 137-151. Véase también más arriba (el arte arabés vs. El Escorial).

71 PINKAS, Cesta, p. 27.

72 VLASÁK, Cesta do Madridu, p. 104.

73 MÜLDNER, Španělsko, p. 28.

74 ČAPEK, Výlet, p. 22.

75 DURYCH, Pout', pp. 105-107. El Escorial es para él un "coloso melancólico", un "juguete para Cíclope" (íbidem); lo que le verdaderamente atraía fueron las pinturas del "cabalista" El Bosco.

76 KYBAL, $O$ Španělsku, p. 81. 
Todos los viajeros checos coinciden en que uno de los centros de educación españoles más importantes es Salamanca. Ya el caballero checo Václav Šašek de Birrkov (1465-67) escribe sobre Salamanca como un lugar donde la ciencia florece como en ningún otro lugar. ${ }^{77}$ Según Vlastimil Kybal, esta es una ciudad universitaria muy agradable, pero su encanto no es obvio para un peregrino sin "sentido especial para la ciencia e historia" ${ }^{78}$ Jiří Guth escribe sobre Salamanca como la Roma española, la madre de las virtudes, ciencias y artes y compara la antigua y famosa universidad salmantina con la Universidad de Coimbra y la Universidad Carlo-Fernandina ${ }^{79}$ Habla del fundador de la Universidad, Alfonso el Sabio, como un gobernante que se dedicó y apoyó a las ciencias con mucho entusiasmo. El conocimiento que se cultivó en la universidad (ya sea teología, derecho o filosofía) alcanzó tal nivel que los ojos de todo el mundo se fijaron en el alto conocimiento de la pequeña ciudad española. ${ }^{80}$ Guth también destaca el hecho de que en Salamanca se desarrollaran las ciencias naturales y matemáticas. A Salamanca viajaron estudiantes y gente curiosa de toda Europa para aprender de sus profesores, al igual los eruditos salmantinos fueron demandados por todo el mundo. ${ }^{81}$ Destaca que en Salamanca se pudiera estudiar también el sistema de Copérnico, rechazado en otros países como herético. ${ }^{82}$

La recepción libre del copernicanismo en Salamanca es también mencionada por Vlastimil Kybal ${ }^{83}$ y Josef Müldner. Además Müldner desarrolla este tema: informa de que en Salamanca se estudiaba y cultivaba la astronomía, fueron corregidas las tablas astronómicas, allí fue también escrita la primera historia española, igual como editados los escritos de Avicena, Platón, Aristóteles y Averroes.$^{84}$ La riqueza intelectual salmantina de la Edad de Oro todavía se refleja en la biblioteca universitaria; según Kybal, entre los manuscritos que contiene se pueden encontrar "tesoros

77 Panoš JAROSLAV, Ve službách Jiříka krále: deníky panoše Jaroslava a Václava Šaška z Bîrkova [En los servicios del rey Jiř́ík: los diarios de criados Jaroslav y Václav Šašek z Bîrkova]. Praha 1940, p. 105.

78 KYBAL, O Španělsku, p. 34.

79 GUTH, Za horama, p. 144. A Salamanca la llama poéticamente "rosa amarilla" (por el color de las piedras de las que están construidos sus edificios históricos). La Universidad Carlo-Fernandina fue declarada por los rescriptos de Fernando III en 1654, existió hasta 1920, cuando la parte checa de la universidad se volvió a llamar Universidad Carolina.

80 GUTH, Za horama, p. 155.

81 Guth y Müldner destacan que también Colón llegó a Salamanca, para discutir sus planes sobre las rutas nuevas a la India con los profesores salmantinos. Véase GUTH, Za horama, p. 153; MÜLDNER, Španělsko, p. 39. Guth también menciona al matemático salmantino Pedro Ciruelo (1470-1548), quien luego trabajó en Francia. En su libro de viaje habla también sobre el teólogo y hebreísta León de Castro (? - alrededor de 1580), enemigo de Luis de León, y Benito Arias Montano; Diego de Covarrubias (1512-1577) y Domingo de Soto (1494-1560) como los representantes de la Escuela de Salamanca, fundada por Francisco de Vittoria; o el reconocido autor de la primera gramática del español (y cosmógrafo) Antonio de Nebrija (1441-1522).

82 GUTH, Za horama, p. 154.

83 KYBAL, Španělsko, p. 39. Tanto Kybal como Müldner subrayan que, por otro lado, en Salamanca no se aceptó el movimiento reformador de los husitas. Por este fenómeno se interesó, por ejemplo, Miguel de Unamuno.

84 MÜLDNER, Španělsko, p. 39. 
desconocidos", menciona específicamente los escritos de los estatutos universitarios árabes del siglo XV o los escritos teológicos y matemáticos, que según él eran las obras que dominaban..$^{85}$

Así, la educación en España de la Edad de Oro es percibida por los viajeros checos como indudablemente avanzada y, de alguna manera, "progresista"; no vemos ninguna idea que pueda poner en duda (o negar completamente) la importancia del conocimiento científico español o el Renacimiento como tal. ${ }^{86}$ Las evaluaciones críticas, sin embargo, aparecen en relación con los niveles intelectual y educativo de su tiempo.

\section{Tiempos gloriosos pasados ¿La abulia como el enemigo de la modernización del mundo intelectual español?}

El desafortunado estado del conocimiento español a finales del siglo XIX e inicios del siglo XX se hace evidente sobre todo en el fondo y en contraposición a la prosperidad cultural e intelectual de períodos anteriores, especialmente en el caso de Salamanca. Según Guth, Salamanca sobrevive sólo gracias a su pasada gloria. ${ }^{87}$ Müldner, igual que Guth, afirma que en su época Salamanca "vive sólo en la sombra de su gloria perdida; entre tiendas miserables y polvorientas vende la educación anticuada de sus profesores." ${ }^{88}$ Vlastimil Kybal es aún más crítico: en la Universidad de Salamanca escuchó conferencias sobre historia antigua y derecho penal, y su impresión fue extremadamente vergonzosa (especialmente porque el conocimiento del profesor era muy bajo e inmaduro); una experiencia muy similar tuvo en Madrid. Según Kybal, todas las universidades españolas de su tiempo "asustaban con el viejo método de enseñanza, basándose en tradiciones muertas y mecánicas de la ciencia obsoleta." ${ }^{89}$

85 KYBAL, $O$ Španělsku, p. 72. Kybal menciona también algunos aspectos negativos con respecto a la biblioteca, ante todo el caos. No hay catálogo y el bibliotecario no sabe exactamente qué hay en la biblioteca.

86 Hans Wantoch ve su causa en el aislamiento de España, según Henrik Morf no se puede hablar de un verdadero Renacimiento español, porque en el ambiente español no se superó la tradición medieval y Victor Klemperer niega el Renacimiento español porque en su opinión, los españoles que vivían en la época del Renacimiento estuvieron "encadenados por cadenas de dogmatismo". Hans WANTOCH, Spanien, das Land Ohne Renaissance, München 1927, pp. 24-26; Henrik MORF, Die Kultur der Gegenwart, ciudad 1909; Victor KLEMPERER, Gibt es eine spanische Renaissance in Logos 16, ciudad 1927, p. XX. Cf. ABELLÁN, Historia II. La edad de oro, pp. 20-21. El Renacimiento español es negado también por José Ortega y Gasset. José ORTEGA Y GASSET, La idea de principio en Leibniz y la evolución de la teoría deductiva II, Madrid 1958, p. 249.

87 GUTH, Za horama, pp. 146-147. Guth, sin embargo, estuvo en Salamanca durante la temporada de verano, en vacaciones, cuando la biblioteca estaba cerrada. Además, como escribe, no habría podido estudiar debido al clima demasiado cálido, porque con tanto calor "silent Musae". El declive de las universidades españolas generalmente se produjo, según Guth, principalmente desde finales del siglo XVIII como resultado de las perturbaciones políticas. Guth también menciona el sistema de las universidades españolas en general. GUTH, Za horama, p. 155.

88 MÜLDNER, ̌̌panělsko, p. 39.

89 KYBAL, $O$ Španělsku, p. 75. Según Kybal, la causa de este descenso es la excesiva cantidad de las universidades igual como su fragmentación; critica el aumento de las universidades pequeñas 
Sobre cierta decadencia del ambiente universitario español hablan también otros viajeros checos. Ota Pinkas escribe sobre la vida estudiantil de Valladolid que perdió su brillo e interés. ${ }^{90}$ Según Jiří Guth, no sólo Salamanca, sino también las ciudades del sur de España ofrecen una triste imagen de la gloria pasada y de la antigua prosperidad (explícitamente menciona, por ejemplo, a Cádiz).$^{91}$ Barcelona, según ellos, representa una excepción; como ha sido mencionado más arriba, los viajeros checos la describen como "más europea", progresiva y moderna. ${ }^{92}$

Sin embargo, la España de finales del siglo XIX e inicios del siglo XX, en comparación con otros países europeos, es descrita en general por los viajeros checos como una nación atrasada en ciertos aspectos. El fenómeno del atraso -que se puede interpretar parcialmente también como un conflicto entre tradicionalismo y modernismo- es percibido a menudo como un rasgo específico de la época. Pero ¿cómo surgió este "retraso", cuál fue su causa? ¿Es sólo un fenómeno temporal o permanente? Vlastimil Kybal está convencido de que es el resultado no sólo de la ociosidad e inercia de los españoles, sino también de las condiciones naturales que son muy desfavorables para cualquier actividad intensa. ${ }^{93} \mathrm{El}$ problema de la inercia general española (que, de hecho, es un estereotipo cultural frecuente asociado con España) está reflejado también por otros viajeros checos. Por ejemplo, Jan Rambousek escribe que los alemanes no podían entender como sobrevive la gente de Granada cuando no hace nada y pasa todos los días en la sombra frente a las cafeterías ${ }^{94}$ Con respecto a esta problemática, recuerda Jiří Guth los versos de Zorrilla:

(“parasitarias”) y acentúa la necesidad de la centralización y modernización de la educación. Ibidem, pp. 75-76. Kybal también se refiere a la pobreza de las universidades españolas: por ejemplo, en Salamanca, sólo la Facultad de Filosofía y Derecho fueron apoyadas por el gobierno, las ciencias naturales y medicina fueron abandonadas por el gobierno y tuvieron que prestarse dinero de la provincia. Ibidem, pp. 73-74.

90 PINKAS, Cesta, p. 17.

91 GUTH, Causerie, p. 20.

92 Véase, por ejemplo, PINKAS, Cesta,pp. 177-178. Según Pinkas, Barcelona es una ciudad moderna, literalmente mundial. Aparte de las impresiones habituales, menciona el ambiente intelectual estimulante de las cafeterías; también describe colecciones maravillosas de los médicos barceloneses (por ejemplo, colecciones de uñas deformadas o los callos de pies (hiperqueratosis). Ibidem, p. 186. Según Kybal, Barcelona es una de las ciudades costeras más atractivas de Europa, todavía en desarrollo, viva tanto intelectualmente como artísticamente. KYBAL, $O$ Španělsku, pp. 21-22. La imagen del ambiente intelectual español a finales del siglo XIX está descrita también por Erazim Vlasák, quien visitó España para participar en la conferencia médica internacional celebrada en 1898 en el "lejano Madrid". A través de la invitación, muestra cómo el comité organizador le ha invitado a una "fiesta científica" y el respeto que tiene la nación española hacia la ciencia en general. VLASÁK, Cesta, p. 37. Dice que no solo él, a pesar de algunas preocupaciones iniciales, salió de España con las mejores impresiones. En su libro describe, en primer lugar, la conferencia propia: por ejemplo, se refiere a una conferencia del histólogo Ramón y Cajal (ganador del Premio Nobel, 1906). Aunque Vlasák no entendía el español, aprecia la retórica excelente de Cajal. Ibidem, p. 49. Además, Vlasák ofrece al lector informaciones breves sobre la historia madrileña, sus monumentos, bibliotecas e instituciones científicas (Archivo Histórico Nacional, Ateneo científico, Literario y Artístico, Biblioteca Nacional); es casi pura descripción, pero cuando aparecen las evaluaciones, son positivas (por otra parte, Vlasák menciona algunos aspectos negativos de la vida cotidiana española).

93 KYBAL, O Španělsku, p. 95.

94 RAMBOUSEK, Toulky, p. 36. 
“Aquí en nuestra buena España - Donde se duerme la siesta - Donde se canta la caña - Donde el trabajo molesta - Y es la vida una cucaña"; y que, de hecho, en el original de Zorrilla continúan con la negación de la actividad filosófica española. ${ }^{95}$

Kybal habla de la afición innata y luego cultivada de los españoles hacia el entretenimiento, y señala que Gautier estaba incluso encantado con la -supuesta- inactividad de los españoles del sur; consideraba muy filosófico que los españoles despreciaran el trabajo y la comodidad, prefiriendo disfrutar de los placeres de la vida y la naturaleza. Según Kybal, Gautier tiene cierta razón; en la ociosidad española ve también la belleza de la "raza del sur de España”, por otro lado, afirma que los españoles ya no pueden vivir al margen de Europa y lo saben, que "el mayor problema de su vida nacional es el problema económico e intelectual". ${ }^{96}$ En general, Kybal afirma que el español es "inmóvil” en el sentido material igual como intelectual: no le gusta trabajar ni pensar, y mucho tiempo lo dedica a la diversión y "laisser-aller" apático. Aunque, según Kybal, los españoles, en ciertos aspectos y virtudes, sobresalen sobre muchos pueblos (siendo una nación moderada, orgullosa, decente y democrática), también se trata de una nación inerte, perezosa y sin instrucción necesaria. Le parece a Kybal como si los españoles no tuvieran ni potencial para el progreso, ni iluminación del espíritu y mejoramiento de sus vidas. ${ }^{97}$

Las opiniones de Kybal no están aisladas en su tiempo, por el contrario, reflejan fielmente el debate que tuvo lugar no sólo en el ambiente español (por ejemplo, en los textos de Américo Castro, Ángel Ganivet, Miguel de Unamuno y otros noventayochistas). Kybal destaca que incluso los mismos españoles son conscientes de sus deficiencias. Por ejemplo, Ángel Ganivet, en su Idearium español (1897), habla de la enfermedad que sufren los españoles y cuya cura es muy difícil. Se trata de la así llamada abulia, es decir, la "pérdida o el debilitamiento severo de la voluntad", que se manifiesta por "no hacer nada" en la vida práctica y por el desenfoque intelectual. Según Ganivet, hay que superar el descenso y agotamiento intelectual y restaurar la vida espiritual igual como prestigio de la nación española. ${ }^{98}$ Argumentos similares y, sobre todo, las demandas de la regeneración intelectual de España, los podemos encontrar también en los trabajos de los representantes de La generación del 98 y de La generación del 14. Si dejamos aparte las preguntas sobre en qué medida las pesimistas opiniones de los representantes de La generación del 98 reflejaron la situación real histórica, la crisis imperial de 1898, el ánimo decadente del fin de siglo y, además, un cierto masoquismo español, ${ }^{99}$ la cuestión sigue siendo

95 GUTH, p. 41. Compara José ZORILLA, De Murcia al cielo, Madrid 1888, p. 13. El verso sigue: “quien parece que medita, reflexiona ó filósofa [...] sueña, está en Babia ó dormita [...] a este sol del mediodia se filosofa tán mal, que España tiene hoy en día en una guitarrería su piedra filosofal.”

96 KYBAL, O Španělsku, p. 96.

97 Ibidem, pp. 102-103.

98 GANIVET, Španělské idearium, pp. 83-86, 88-89.

99 Compara QUESADA MARCO, Historia, pp. 192-195. Sobre el tema del regeneracionismo veáse, por ejemplo, Vicent L. SALAVERT FABIANI, El regeneracionismo en España: política, educación, ciencia y sociedad, Valencia 2007. Véase también Darina MARTYKÁNOVÁ, "Los pueblos viriles y el yugo del caballero español. La virilidad como problema nacional en el regeneracionismo español (1890s-1910s)", Cuadernos de Historia Contemporánea 39, pp. 19-37. 
cómo quisieron resolver el así llamado "problema español”. Pero, por ahora, lo que nos interesa sobretodo es como habrían resuelto este problema los viajeros checos.

\section{¿Hispanización versus europeización? ¡A españolizar Checoslovaquia con el espíritu de Don Quijote!}

Ota Pinkas no duda de que -con la buena voluntad del pueblo español, y con mayor diligencia- el país seguramente se recuperará y se convertirá en uno de los países más ricos y bellos de Europa. ${ }^{100}$ Según Vlastimil Kybal, el potencial fuerte y completo de España, las poderosas capacidades intelectuales de la raza española, se realizarán plenamente en contacto con el mundo extranjero. ${ }^{101}$ Pero, ¿cómo se realizará esta modernización? ¿Y en qué medida? Definitivamente no tan radicalmente como lo propuso La generación del 14 y José Ortega y Gasset quien declaró la necesidad de "quemar" la España tradicional y buscar, construir el futuro de España, es decir, la España modernizada y europeizada (que para Ortega significó principalmente germanizada). ${ }^{102}$

Kybal y otros viajeros checos son conscientes del hecho de que la nación española es una nación que está orgullosa de sus tradiciones, que las evalúa positivamente y las cuida. Según Kybal, esta continuidad histórica y moral de la nación es un signo de fortaleza interior, no de decadencia; el signo del descenso sería lo contrario, es decir, el desdén por la tradición e imitación de otras naciones. Sin embargo, el español no vive para lo extranjero o según lo extranjero, pero -como cada nación sana y grande- para sí mismo y según lo suyo, sin prestar mucha atención a la opinión exterior. ${ }^{103}$ Pinkas también opina que al español le gusta permanecer en las tradiciones, no le atraen las novedades. ${ }^{104}$ Jan Rambousek, en comparación con el carácter internacional, también aprecia los específicos y las tradiciones nacionales ${ }^{105} \mathrm{y}$, por último, pero no menos importante, Karel Čapek. Čapek constata que la nación española, aparte de los ingleses, ha sido capaz de preservar su propia manera de vivir lo mejor de todos.

100 PINKAS, Cesta, p. 20.

101 KYBAL, $O$ Španělsku, p. 110.

102 "La tradición! La realidad tradicional en España ha consistido precisamente en el aniquilamiento progresivo de la posibilidad España. No, no podemos seguir la tradición. Español significa para mí una altísima promesa que sólo en casos de extrema rareza ha sido cumplida. [...] En un grande, doloroso incendio habríamos de quemar la inerte apariencia tradicional, la España que ha sido, y luego, entre las cenizas bien cribadas, hallaremos como una gema iridiscente, la España que pudo ser", José ORTEGA Y GASSET, Meditaciones del Quijote, Madrid 1914, p. 133. Para Ortega, España es el "promontorio espiritual de Europa". Ibidem, p. 129. En otras partes, contrasta la cultura germánica y la mediterránea (latina) como cultura de la realidad profunda versus cultura superficial, filosóficamente y científicamente infértil.

103 KYBAL, O Španělsku, p. 84.

104 PINKAS, p. 14. Del mismo modo, habla sobre Madrid como una ciudad española pura, que, a diferencia de otras ciudades residenciales, carece de carácter cosmopolita, una ciudad que aún no ha renunciado a su carácter nacional. Ibidem, p. 31.

105 RAMBOUSEK, Toulky, p. 28. 
Aprecia el hecho de que los españoles prefieran su vieja España antes que el recubrimiento de la civilización internacional; según Čapek el sevillano nunca se convertirá en un buen europeo internacional porque ni siquiera se convertirá en un madrileño. ${ }^{106}$ Le encanta ver que los españoles son realmente españoles; cuanto más "españoles" eran, más los quería y más los apreciaba. La idea de la reciprocidad y la cooperación europeas sólo los valora positivamente en caso de la preservación de las diferencias culturales únicas. ${ }^{107}$

Según Kybal, lo único que deberían hacer los españoles es dejar de ser inertes, aprender a valorar el trabajo, el progreso y la educación; reconciliar su ego de hidalgo con la conciencia de ciudadano moderno y el patriotismo. ${ }^{108}$ No sólo Kybal, sino también otros viajeros checos, aprecian los detalles y la singularidad de la cultura española; que puede, a primera vista, causar temores o malentendidos, pero con un conocimiento más profundo se convierte en encantamiento y amor comprensivos. Todos los viajeros checos regresan a su propio país desde el más allá de los Pirineos con la convicción de que España es un país que ofrece belleza y tesoros insospechados, un país que vale la pena conocer e indudablemente un país al que les gustaría regresar. Si mencionan la necesidad de modernizar España, tienden a las ideas e ideales unamunianos, es decir, la revitalización del ambiente intelectual español debería suceder respetando y preservando "lo español" (la esencia española). Además, según Václav Černý, si el hispanismo fuera idéntico con el quijotismo, también sería posible aceptar la demanda de Unamuno - a "españolizar a Europa" (como la presuposición de una posterior europeización de España); después de todo, el mundo podría ser sumamente honrado con este "a españolizar a Europa."109

\author{
por Jana Černá(Pilsen) \\ jacerna@kfi.zcu.cz \\ (Escrito en español por la autora)
}

\title{
BIBLIOGRAFÍA
}

ABELLÁN, José Luis, Historia crítica del pensamiento español I. Metodología e introducción histórica, Madrid: Espasa Calpe, 1979.

ABELLÁN, José Luis, Historia crítica del pensamiento español II. La edad de oro, Madrid: Espasa Calpe, 1986.

BĚLIČ, Oldřich - FORBELSKÝ, Josef, Dějiny španělské literatury [Historia de la literatura española], Praha: SPN, 1984.

106 ČAPEK, Výlet, p. 146. Considera si esta resistencia a las influencias exteriores de moda es causada por el clima o la posición casi insular de España para concluir que es principalmente una cuestión de carácter (ibidem).

107 Ibidem, pp. 181-182.

108 KYBAL, ̌̌panělsko, p. 110.

109 ČERNÝ, "Rektora", in: Václav Černý, Studie o španělské literatuře [Estudios sobre la literatura española], Praha 2008, p. 316. Kybal escribe sobre Don Quijote como una obra típica española, que además tiene un significado universal y, por lo tanto, también puede servir a la creación y al esfuerzo cultural checo. KYBAL, Velikáni, p. 56. 
BINKOVÁ, Simona, "La imagen de España en Bohemia de finales del siglo XIX. (Los libros de viaje de Jiří Guth, Pavel Durdík y Erazim Vlasák), in: Josef Opatrný (ed.), Las relaciones checo-españolas, Praha: Karolinum, 2007, pp. 199-217.

CARO BAROJA, Julio, El mito del carácter nacional, Madrid: Caro Raggio, 2004.

ČAPEK, Karel, Výlet do Španěl literatury [Viaje a España], Praha: Fr. Borový, 1940.

ČERNÁ, Jana, Dál a dál za Herkulovy sloupy: př́rodní tajemství Nového světa a španělská renesanční filosofie a věda literatury [Más allá detrás de las columnas de Hércules: los misterios naturales del Nuevo mundo y la filosofía y ciencia españolas], Praha: Triton, 2016.

ČERNÁ, Jana, Očitá svědecví: Španělsko, Nový svět a změna vědeckého komunikačního paradigmatu literatury [Testimonios oculares: España, Nuevo Mundo y el cambio del paradigma comunicativo científico de la literatura], Červený Kostelec: Pavel Mervart, 2012.

ČERNÁ, Jana, “¿Qué se debe a España?: Spor o význam Španělska v evropských intelektuálních dějinách", Dějiny - teorie - kritika 9, Praha 2009, pp. 230-245.

ČERNÝ, Václav, Studie o španělské literatuře literatury [Estudios sobre la literatura española], Praha: Cherm, 2008.

DURYCH, Jaroslav, Pout' do Španělska [Peregrinación a España], ed. Michal Šiml, Tři toulky Evropou [Tres paseos por Europa], Praha: Kra, 1993.

GANIVET, Ángel, Idearium español, Granada: Tip. Lit. Vda. e Hijos de Sabatel, 1897.

GANIVET, Ángel, Španělské idearium [Ideario español], Chomutov: L. Marek, 2007.

GUTH, Jiři, Causerie z cest, řada I, Španělsko [Causerie de viajes, serie I, España], Praha: F. Šimáček, 1891.

GUTH, Jiři, Za horama Pyrenejskýma [Detrás de las montañas de los Pirineos], Praha: Máj, 1902.

CHALUPA, Jiří, Španělsko [España], Praha: Libri, 2005.

CHMELNÍČEK, Jiři, Cesta do Francouz a do Španěl, jíž vykonal a sepsal Jiří Chmelníček [Viaje a Francia y España hecho y escrito por Jiří Chmelníček], tomo I. Praha: Dědictwí sw. Cyrilla a Methodia, 1869.

JAROSLAV, Panos, Ve službách Jiříka krále: deníky panoše Jaroslava a Václava Šaška z Bî́kova [En los servicios del rey Jiř́ík: los diarios de criados Jaroslav y Václav Šašek z Bứrova], Praha: ELK Evropský literární klub, 1940.

JUDERÍAS, Julián, La leyenda negra de España, ed. Luis Español, Madrid: La Esfera de los Libros. Madrid, 2014.

KYBAL, Vlastimil, Velikáni španělských dějin [Los grandes de la historia española], Praha; Jednota československých matematiků a fysiků, 1935.

KYBAL, Vlastimil, O Španělsku. Cestovní dojmy a úvahy [Sobre España. Las impresiones y reflexiones de viaje], Praha: Miloš Procházka, 1928.

MÜLDNER, Josef, Španělsko včera a dnes [España ayer y hoy], Praha: Česká grafická unie, 1937.

NAVARRO BROTÒNS, Víctor - EAMON, William, Más allá de la Leyenda Negra. España y la Revolución Científica. Beyond the Black Legend: Spain and the Scientific Revolution, Valencia, Universitat de València: Consejo Superior de Investigaciones Científicas, CSIC, Instituto de Historia de la Ciencia y Documentación, 2007.

Lva Viléma z Kounic Cesta z Janova do Hispánie, 1636, in: Simona BINKOVÁ, Česká touha cestovatelská [El deseo viajero checo], Praha: Odeon, 1989.

OPATRNÝ, Josef, "La imagen de España entre los viajeros checoslovacos de entreguerras. No solamente Karel Čapek”, in: Josef Opatrný (ed.), Las relaciones checo-españolas, Praha: Karolinum, 2007, pp. 219-230.

ORTEGA Y GASSET, José, La idea de principio en Leibniz y la evolución de la teoría deductiva II, Madrid-Buenos Aires: Biblioteca de la Revista de Occidente, 1958.

ORTEGA y GASSET, José, Meditaciones del Quijote, Madrid: Catedra, 1914.

PEDAUYÉ, Antonio, "Las relaciones hispano-checas a lo largo de la historia. Aproximación a algunos períodos de particular interés", in: Josef Opatrný, Las relaciones checo-españolas, Praha: Karolinum, 2007, pp. 9-21.

PÉREZ, Joseph, La leyenda negra, Madrid: Gadir, 2009.

PINKAS, Ota, Cesta po Španělích [Viaje por España], Praha: Ota Pinkas, 1880. 
PUERTO SARMIENTO, Javier, La leyenda verde. Naturaleza, sanidad y ciencia en la corte de Felipe II (1527-1598), Valladolid: Junta de Castilla y León, 2003.

QUESADA MARCO, Sebastian, Historia intelectual de España, Madrid: Acento, 2004.

RAMBOUSEK, Jan, Toulky po Španělsku [Paseos por España], Praha: J. Mrkvička, 1926.

ROSŮLEK, Jan Václav, Lístky ze Španěl [Cartas de España], Praha: Václav Petr, 1929.

SANTOVEÑA SETIÉN, Antonio, Marcelino Menéndez Pelayo: revisión crítico-biográfica de un pensador católico, Santander: Asamblea Regional de Cantabria, D.L., 1994.

de UNAMUNO, Miguel, Algunas consideraciones sobre la literatura hispanoamericana, Madrid: Austral, 1968.

de UNAMUNO, Miguel, En torno al casticismo, Madrid: Biblioteca Nueva, 1996.

de UNAMUNO, Miguel, Španělské essaye [Essaye españoles], Brno: Vetus Via, 1997.

VALERA, Juan, Sobre el concepto que hoy se forma de España, in: J. Valera, Obras completas, tomo III, Madrid: Aquilar, 1958.

VLASÁK, Erazim, Cesta do Madridu [Viaje a Madrid], Praha: Erazim Vlasák, 1899.

WANTOCH, Hans, Spanien, das Land Ohne Renaissance, München: Müller, 1927.

ZORILLA, José, De Murcia al cielo, Madrid: R. Velasco, 1888.

\section{Breve información sobre la autora}

Jana Černá es Doctora en Historia de la Ciencia y Doctora de Filosofía por la Universidad de Bohemia Occidental, profesora asistente e investigadora científica en la misma universidad, actualmente Marie Curie Fellow (Instituto de Historia, CCHS, CSIC, Madrid, 2019-2021). Ha participado en varios proyectos de investigación dedicados a temas de historia de filosofía e historia cultural de la ciencia (tanto nacionales como internacionales). A las áreas principales de su investigación pertenecen: historia natural, medicina, materia medica y filosofía natural de los siglos XVI y XVII (sobre todo, en el contexto del mundo iberoamericano y también con respecto a sus relaciones con el ambiente centroeuropeo). Ha publicado más de veinte artículos sobre esta problemática (en checo, inglés y español) en revistas nacionales e internacionales y dos monografías (en checo). Ha presentado su investigación en congresos y encuentros científicos internacionales (en la República Checa, España, Portugal, Inglaterra, Brasil, México y Croacia). Ha realizado varias estancias de investigación en España (Madrid, Barcelona, Salamanca, Valencia, Sevilla), México (Ciudad de México, Beca de Excelencia del Gobierno de México, MSCA) o Austria (Viena). Imparte los cursos de filosofía renacentista y moderna, historia cultural de la ciencia, filosofía de comunicación, interpretación de textos filosóficos hispanos/ ingleses, metodología de las humanidades, etc.); ha supervisado más de 40 tesis de Grado y una tesis de doctorado. 